\title{
Thermal characterization of fibrous aerogel blanket
}

\author{
Ákos Lakatos ${ }^{1, *}$, Anton Trnik ${ }^{2}$ \\ ${ }^{1}$ University of Debrecen, Faculty of Engineering, Department of Building Services and Building \\ Engineering, 4028, Debrecen, Ótemetö str. 2-4, Hungary \\ ${ }^{2}$ Constantine the Philosopher University in Nitra, Faculty of Natural Sciences, Department of Physics, \\ Tr. A Hlinku 1, 94974 Nitra, Slovakia
}

\begin{abstract}
Nowadays, the application of thermal insulation materials both by the existing and by new buildings is one of the most important actions in order to reduce the energy loss of buildings. Besides the use of the conventional insulations (plastic foams and wool materials) aerogel is one of the most promising thermal insulation material. Aerogels, one of the lightest solid materials available today, are manufactured through the combination of a polymer with a solvent forming a gel. For buildings the fibre reinforced ones are the mainly used types. It is produced by adding the liquid-solid solution to the fibrous batting. In this paper changes in the thermal performance of the aerogel blanket will be followed after thermal annealing. The samples will be put under isothermal heat treatments at 70 ${ }^{\circ} \mathrm{C}$ for 6 weeks, as well as they will be put under thermal treatment at higher temperatures (from $70{ }^{\circ} \mathrm{C}$ till $210^{\circ} \mathrm{C}$ ) for 1 day. The changes in the thermal conductivity will be followed by Holometrix Lambda heat flow meter, as well as, Differential Scanning Calorimetry results will be presented. From the measured values, thermal properties will be calculated. In this paper we will try to clarify the role played by thermal annealing in thermal diffusivity.
\end{abstract}

\section{Introduction}

These days the building sector is one of the key sectors for cost-efficient savings; furthermore it was previously presented that at least $40-60 \%$ of the total final energy consumption originates from buildings. In Hungary approximately the $70-80 \%$ of the buildings needs to be refurbished and/or renovated. With the stricter and stricter regulations thicker (approx. $20 \mathrm{~cm}$ ) insulation should be applied. [1] Nowadays, the commonly used insulation materials are the foamy and the fibrous materials, while the use of the nanotechnological/advanced/super insulation materials e.g.: aerogel is also widespread. [2-6] Heat insulation materials are subjected to different temperature and humidity conditions and their thermal performance can vary during a controlled external impacts. [7] Bulk aerogel is an open cell (porous) material with low density, furthermore with cells on the nanoscale. It is prepared from supercritical drying of various types of gels, and it is most

*Corresponding author: alakatos@eng.unideb.hu 
commonly made from silica gel. [2] It is said by Baetens and his co-author in Ref. [6] that aerogel is one of the most important super-insulation materials with lower than $0.025 \mathrm{~W} /(\mathrm{m}$ $\mathrm{K})$, and more specifically lower thermal conductivity than $0.018 \mathrm{~W} /(\mathrm{m} \mathrm{K})$. It is further reported in Ref. [7-10] It is reported in several papers that aerogel is one of the most promising insulation materials. In a recent paper, it was presented that temperature and humidity have significant effect on the thermal conductivity of the aerogel blanket. [10] Those changes and results will be further reflected and will be presented in brief. Specific heat capacity results, carried out with differential scanning calorimetry, will be used for thermal properties calculations. The effect of the change in the temperature of the environment (ageing) can be modelled with thermal annealing at not-general temperatures. Certainly, thermal annealing of the samples at high temperatures would never be experienced in typical outdoor climate conditions; it can happen that it will generate unrealistic aging issues. For these reasons, thermal annealing processes for modelling the ageing phenomena of the building materials are usually executed near $70{ }^{\circ} \mathrm{C}$. The ageing of materials can be done by irradiation (infrared or ultra-violet) as well as by thermal annealing. However, it is well known that moisture has unwanted effects too, but it is not taken as ageing process. [10] Based on the pre-test of the samples, where we did not observe any changes after annealing the samples at $70{ }^{\circ} \mathrm{C}$ for weeks, we have gone further with the experiments and tested the samples at elevated temperatures $\left(100-210^{\circ} \mathrm{C}\right)$. These temperatures can appear if HVAC systems or pipes transporting hot fluids or steams should be insulated. As well as it can happen industrial or power generating cases.

\section{Materials and methods}

For the measurements glass fibre reinforced aerogel was used with the following properties (see Table 1).

Table 1. The material properties [10]

\begin{tabular}{|c|c|}
\hline Thermal Conductivity via Guarded Hot Plate & $0.0131 \mathrm{~W} /(\mathrm{m} \mathrm{K})$ at $10^{\circ} \mathrm{C}$ \\
\hline Specific Heat Capacity & $1.000 \mathrm{~kJ} /(\mathrm{kg} \mathrm{K})$ at $40^{\circ} \mathrm{C}$ \\
\hline Density $\left[\mathbf{k g} / \mathbf{m}^{3}\right]$ & 150 \\
\hline Porosity & $92 \%$ \\
\hline
\end{tabular}

\subsection{Heat treatments of the samples}

The heat-treating of the samples were executed in the VentiCell 111 drying apparatus once at $70{ }^{\circ} \mathrm{C}$ for 42 days and at $70,100,130,150,180$, and $210{ }^{\circ} \mathrm{C}$ for 1 day, one after the other. With this device materials can be dried at different air temperatures (up to $250{ }^{\circ} \mathrm{C}$ ). It works with hot air circulation using an inbuilt ventilator. [10] The measurements were performed according to the ISO 12664 and 12667 standards. The measurements were carried out after drying (thermal annealing) the samples at $70{ }^{\circ} \mathrm{C}$ similarly as it was presented in Ref. [10]. For measuring the thermal conductivity of the samples, Lambda 2000 Heat flow meter (HFM) was used. This equipment is designed to determine the thermal conductivity of insulation materials in accordance with ASTM C518 standard. The measurement order and the equipment are presented in Ref. [3, 7, 8, 10]. The thermal conductivities are presented in Ref. [10]. 


\subsection{Differential Scanning Calorimetry measurements}

The measurement for determination of the specific heat capacity $c_{p}$ was performed by differential scanning calorimetry, namely apparatus DSC 822e from Mettler Toledo, together with a Julabo FT 900 cooling device. The temperature interval was from $25{ }^{\circ} \mathrm{C}$ to $300{ }^{\circ} \mathrm{C}$ with the heating rate of $10{ }^{\circ} \mathrm{C} / \mathrm{min}$ and with $5 \mathrm{~min}$ isothermal regime before and after linear heating. The samples $(\sim 9 \mathrm{mg})$ were placed into an aluminum crucible with lid and a volume of $40 \mathrm{~mm}^{3}$. All the measurements were done in an air atmosphere with a flow rate of $50 \mathrm{~mL} / \mathrm{min}$. The specific heat capacity as a function of temperature was calculated from the measured heat flow data according to standard DIN 51007. The way to make quantitative measurements of the heat capacity is to use sapphire as the calibrant, because its specific heat capacity is well documented in the literature. Thus, the procedure for determining the specific heat capacity of materials consists of the following three identical steps:

1) Measurement of a blank (empty crucibles); 2) Measurement of a reference sample (sapphire standard); 3) Measurement of the sample.

The calculation was carried out using the equation

$$
c_{p}=c_{p c}\left(m_{c}\left(A_{s}-A_{b}\right)\right) /\left(m_{s}\left(A_{c}-A_{b}\right)\right)
$$

where $A_{b}, A_{s}$, and $A_{c}$ (in $\mathrm{W} / \mathrm{g}$ ) are the measured amplitudes (heat flows) of the blank, sample, and sapphire, respectively. Moreover, $m_{c}$ and $m_{s}$ (in $\mathrm{g}$ ) are the mass of the sapphire and sample, respectively, and $c_{p c}($ in $\mathrm{kJ} /(\mathrm{kg} \mathrm{K}))$ is the specific heat capacity of sapphire.

\subsection{The calculated material properties}

\subsubsection{Thermal diffusivity}

In heat transfer analysis, thermal diffusivity $(\alpha)$ is the thermal conductivity $(\lambda)$ divided by density $(\rho)$ and specific heat capacity $\left(c_{p}\right)$ at constant pressure. It measures the rate of transfer of heat in a material from the hot end to the cold end. [3] It usually used for transient or un-steady cases.

$$
\alpha=\lambda /\left(\rho c_{p}\right)
$$

One way to view thermal diffusivity is as the ratio of the time $(t)$ derivative of temperature to its curvature, quantifying the rate at which temperature $(T)$ concavity is "smoothed out". In a sense, thermal diffusivity is the measure of thermal inertia.[3] In a substance with high thermal diffusivity, heat moves rapidly through it because the substance conducts heat quickly relative to its volumetric heat capacity or 'thermal bulk'. The physical meaning behind thermal diffusivity is associated with the speed of propagation of heat during changes of temperature over time. [11]

$$
\partial T / \partial t=\alpha \nabla^{2} T
$$

Thermal conductivities and thermal diffusivities of insulation materials are usually determined by steady-state or transient methods, such as the guarded hot-plate method, the radial heat-flow method, the hot-wire method as well as the laser flash method. [12] 


\subsubsection{Thermal effusivity}

The second thermal property needed in time-varying problems is thermal effusivity (e) defined as:

$$
e=\left(\lambda \rho c_{p}\right)^{1 / 2}
$$

A material's thermal effusivity is a measure of its ability to exchange thermal energy with its surroundings. [11]

\section{Results and discussion}

\subsection{Changes in the thermal properties}

The results of the measured thermal conductivities were presented in Ref. 10. It was highlighted there, that after an isothermal heat-treating from 1 to 42 days at $70{ }^{\circ} \mathrm{C}$ no changes both in the density of the samples and in their thermal conductivity were observed. It was measured to $0.0171 \pm 0.002 \mathrm{~W} /(\mathrm{m} \mathrm{K})$. Furthermore, in the density only a slight decrease was manifested after 42 days $(0.5 \%)$. Here has to be mentioned that after isochronal investigations (for 1 day), where the temperature was varied to 100, 130, 150, 180 , and $210^{\circ} \mathrm{C}$ significant changes both in the thermal conductivity and in the density of the material were found (see Table 2).

Table 2. The specific heat capacity, thermal conductivity, and density of studied aerogel sample

\begin{tabular}{|l|c|c|c|c|c|c|}
\hline & $\mathbf{7 0}^{\circ} \mathbf{C}$ & $\mathbf{1 0 0}^{\circ} \mathbf{C}$ & $\mathbf{1 3 0}^{\circ} \mathbf{C}$ & $\mathbf{1 5 0}^{\circ} \mathbf{C}$ & $\mathbf{1 8 0}^{\circ} \mathbf{C}$ & $\mathbf{2 1 0}^{\circ} \mathbf{C}$ \\
\hline$\lambda[\mathbf{W} /(\mathbf{m ~ K})]^{*}$ & 0.0171 & 0.0171 & 0.0162 & 0.0181 & 0.0180 & 0.0200 \\
\hline $\boldsymbol{\rho}\left[\mathbf{k g} / \mathbf{m}^{3}\right]$ & 150.17 & 150.24 & 150.24 & 148.68 & 147.96 & 147.48 \\
\hline$c_{\boldsymbol{p}}[\mathbf{J} /(\mathbf{k g ~ K})]$ & 1795 & 1853 & 1962 & 2128 & 2369 & 2656 \\
\hline
\end{tabular}

*values of thermal conductivity were taken from Ref.[10]

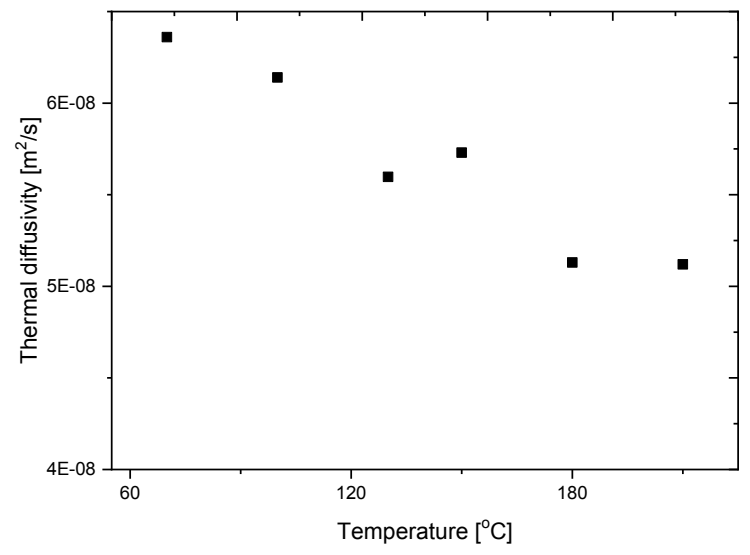


Fig. 1.a The calculated thermal diffusivity

From Fig 1.a and $\mathrm{b}$ one could detect a decreasing thermal diffusivity, as well as, an increasing thermal effusivity. These are caused by once the monotonous increase of the specific heat capacity and the decrease of the density as well as, the increase of thermal conductivity after annealing at $150^{\circ} \mathrm{C}$. As one can see that, the results are in the same order of magnitude $\left(10^{-8}\right)$. In Ref. [13] it was presented that the measurements of thermal conductivity and thermal diffusivity of thermal insulation materials are very important. They investigated both commercially available and fibrous insulation materials. They reached that, the thermal diffusivity values are about $10^{-7} \mathrm{~m}^{2} / \mathrm{s}$. In Ref. [14] the authors executed investigations on the bio-based insulation materials with high density $(>300$ $\left.\mathrm{kg} / \mathrm{m}^{3}\right)$ and with high thermal conductivity $(0.1-0.3 \mathrm{~W} /(\mathrm{m} \mathrm{K}))$. Therefore, they reached 1$2 * 10^{-7} \mathrm{~m}^{2} / \mathrm{s}$ for the thermal diffusivity, from the measured specific heats with DSC, too.

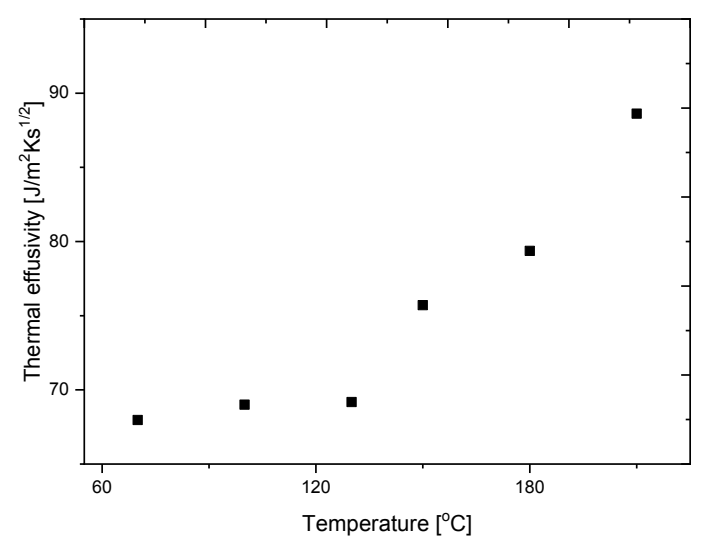

Fig. 1.b The calculated thermal effusivity

In order to go deeper in the background of the changes both in the thermal diffusivity and in the thermal effusivity Fig. 2. was created. From Fig. 2 one can see the rapidly increasing specific heat capacity with the temperature, while the density is only slightly changes. The thermal conductivity until $130{ }^{\circ} \mathrm{C}$ is scattering around $0 \%$ with $\pm 3 \%$ which value is in good correspondence with the measurement accuracy of the heat flow meter equipment, see Ref. [8] The thermal diffusion values are mainly caused by the rapid change of the specific heat capacity. The calculated $10^{-8} \mathrm{~m}^{2} / \mathrm{s}$ value has good correlation with the above mentioned ones presented in the literature.

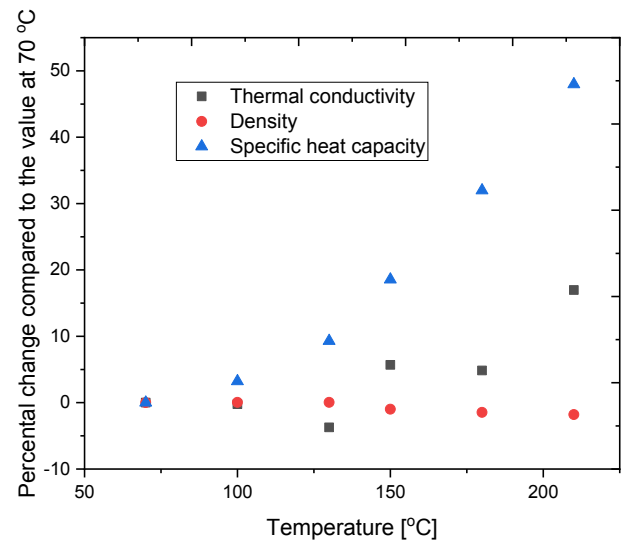


Fig. 2. The percentile change in the measured values

\section{Conclusions}

In this paper thermal investigations were introduced carried out on heat annealed glass fibre-reinforced aerogel. As well as calculations for the thermal diffusivity and for thermal effusivity were presented, based on measured thermal conductivities, densities and specific heat capacities. It was shown previously that after isothermal annealing both the density and the thermal conductivity is constant. In this work the role played by thermal diffusivity, as the quantity that governs the speed of heat propagation in transient problems, has been analysed. It was highlighted, that in the isochronal heat-treating case significant changes were found in the material properties after $150{ }^{\circ} \mathrm{C}$. The increasing thermal diffusivity causes decreasing thermal insulation capability.

The research was financed by the Higher Education Institutional Excellence Programme of the Ministry of Human Capacities in Hungary, within the framework of the Energetics thematic programme of the University of Debrecen.

\section{References}

1. F. Kalmár, 11th Conference for Building Physics Dresden, Germany, (2002);, 103-112.

2. M. Aegerter, N. Leventis, M. Koebel. (Eds.): Aerogels Handbook. (New York: New York Springer 2011 537-564).

3. Á. Lakatos, Mat. and Str. 50:1(2) (2017)

4. K. Ghazi Wakili, Th., Stahl, E. Heiduk, M. Schuss, R. Vonbank, U. Pont, C. Sustr, D. Wolosiuk, A. Mahdavi, En. Proc. 78 (2015) doi:10.1016/j.egypro.2015.11.027

5. E. Cuce, P.M. Cuce, C.J. Wood, S.B. Riffat, Ren. and Sust. En. Rev. 34 273-299. (2014)

6. R. Baetens, B.P. Jelle, A. Gustavsen, En. and Build. 43 761-769. (2011)

7. Á. Lakatos, En. and Build. 139 506-516. (2017)

8. Á. Lakatos, J. of Therm. Anal. and Cal., 133 1: 329-335. (2018)

9. Á. Lakatos, AIP Conference Proceedings, 1866. 030003. 1-6. (2017)

10. Á. Lakatos, En. and Build. 185, 103-111 (2019)

11. A. Salazar, On thermal diffusivity, Eur. J. Phys. 24 351-358 (2003)

12. G. Wei, X. Zhang, F. Yu, K. Chen, Int. j. of Thermophys. 27.1 235-243. (2006)

13. I. Boulaoued, I. Amara, A. Mhimid, Int. J. of Heat and Techn. 34.2 325-331. (2016)

14. M. Lamrani, N. Laaroussi, A. Khabbazi, M. Khalfaoui, M. Garoum, A. Feiz, Case Stud. in Const. Mat. 7, 294-304 (2017) 